\title{
Utilization of Mechanical Ventilation for Asthma Exacerbations: Analysis of a National Database
}

\author{
Rahul Nanchal MD, Gagan Kumar MD, Tillotama Majumdar MD, Amit Taneja MD, \\ Jayshil Patel MD, Gaurav Dagar MD, Elizabeth R Jacobs, and Jeff Whittle MD
}

\begin{abstract}
BACKGROUND: The current frequency of noninvasive (NIV) and invasive mechanical ventilation use in asthma exacerbations (AEs) and the relationship to outcomes are unknown. METHODS: We used the Healthcare Cost and Utilization Project Nationwide Inpatient Sample to identify patients discharged with a principal diagnosis of AE. For each discharge, we determined whether NIV or invasive mechanical ventilation was initiated during the first 2 hospital days. Using multivariate logistic regression to adjust for potential confounders, we determined whether use of mechanical ventilation and in-hospital mortality changed between 2000 and 2008. RESULTS: The number of AEs increased by $15.8 \%$ from 2000 to 2008 . The proportion of admissions for which invasive mechanical ventilation was used during the first 2 days decreased from $1.4 \%$ in 2000 to $0.73 \%$ in 2008, whereas NIV use increased from $0.34 \%$ to $1.9 \%$. The adjusted mortality from AEs requiring NIV or invasive mechanical ventilation was unchanged from 2000 to 2008 . The hospital stay was also unchanged. CONCLUSIONS: There was a substantial increase in the use of mechanical ventilation, accompanied by a shift from invasive mechanical ventilation to NIV. Although we could not determine the clinical reasons for this increase, hospital stay and mortality were unchanged. A randomized trial is needed to determine whether NIV can improve outcomes in AEs before widespread adoption makes it impossible to conduct such a trial. Key words: asthma; mechanical ventilation; intensive care unit. [Respir Care 2014;59(5):644-653. @ 2014 Daedalus Enterprises]
\end{abstract}

\section{Introduction}

Asthma is a common illness with a spectrum of presentation ranging from mild disease to a severe resistant phenotype resulting in respiratory failure requiring mechanical ventilation. Asthma exacerbations (AEs) account for

\footnotetext{
The authors are from the Milwaukee Initiative in Critical Care Outcomes Research (MICCOR) Group of Investigators. Drs Nanchal, Kumar, Majumdar, Taneja, Patel, Dagar, and Jacobs are affiliated with the Department of Medicine, Division of Pulmonary and Critical Care Medicine, and Dr Whittle is affiliated with the Department of Medicine, Division of General Internal Medicine, Medical College of Wisconsin, Milwaukee, Wisconsin. Dr Whittle is also affiliated with the Primary Care Division, Clement J Zablocki Veterans Affairs Medical Center, Milwaukee, Wisconsin.
}

Supplementary material related to this paper is available at http:// www.rcjournal.com.

Drs Nanchal and Kumar are co-first authors.

The authors have declared no conflicts of interest. $\sim 2$ million emergency department visits annually in the United States, $25 \%$ of which lead to hospitalization. ${ }^{1}$ Although asthma-related hospitalizations rarely end in death, ${ }^{2}$ $\sim 10 \%$ do include an ICU stay $^{3}$. A significant fraction of

See the Related Editorial on Page 794

patients hospitalized for AEs (2-4\%) require mechanical ventilation; their mortality has been reported to be as high as $22 \% .^{3-8}$ However, most studies of the outcomes of patients hospitalized for asthma reflect the experience at a single center, limiting inference about national outcomes.

Correspondence: Rahul Nanchal MD, Department of Medicine, Division of Pulmonary and Critical Care Medicine, Medical College of Wisconsin, 9200 West Wisconsin Avenue, E 5200, Milwaukee, WI 53226. E-mail: rnanchal@mcw.edu.

DOI: $10.4187 /$ respcare. 02505 
The use of noninvasive ventilation (NIV) for acute respiratory failure has gained wide acceptance, and indications for its use have expanded over the past decade. ${ }^{9,10}$ Improved outcomes from the avoidance of complications of endotracheal intubation and invasive mechanical ventilation have been demonstrated for diseases such as exacerbations of COPD, ${ }^{11,12}$ acute cardiogenic pulmonary edema, ${ }^{13}$ and respiratory failure in immunocompromised patients. ${ }^{14}$ Although sporadic single-center reports have described NIV use for AEs, its benefits in this setting are not well established ${ }^{15-19}$; hence, its use remains controversial. We suspect, however, that increasing familiarity with the use of NIV combined with the fact that it can be used outside of the ICU has led to its broader use in AEs.

We therefore carried out the present study to describe changes in the patterns of invasive mechanical ventilation and NIV use in AEs over time. We hypothesized that NIV use rose while invasive mechanical ventilation use fell since NIV has become more widely used for other indications. To test our hypothesis, enhance the generalizability of our results, and detect small but important differences, we utilized a large nationally representative administrative database from 2000 to 2008 . To better understand the impact of changes in the use of these modalities, we also describe the associated changes in mortality and other outcomes.

\section{Methods}

\section{Data Source}

We used the Healthcare Cost and Utilization Project Nationwide Inpatient Sample (NIS), which is an administrative database that was created by the Agency for Healthcare Research and Quality and that contains data from an $\sim 20 \%$ sample of United States community hospitals. Each hospitalization is treated as an individual entry in the database; the principal diagnosis, up to 14 secondary diagnoses, and 15 procedural diagnoses associated with that stay are coded using the International Classification of Diseases, 9th Revision, Clinical Modification (ICD-9-CM). The details of NIS can be found online. ${ }^{20}$ We used data from 2000 to 2008 for the purposes of our study.

Since we used a publically available database without patient identifiers, our study was examined and found exempt from formal review by the Institutional Review Board of the Medical College of Wisconsin.

\section{Study Population}

We identified adult patients (18 y of age or older) discharged with a principal diagnosis of AE (ICD-9-CM code 493.XX). We excluded patients with a secondary diagnosis of pneumonia (ICD-9-CM codes 480-486), severe sep-

\section{QUICK LOOK}

\section{Current knowledge}

Asthma exacerbations (AEs) account for $\sim 2$ million emergency department visits annually in United States, one quarter of which lead to hospitalization. Approximately $10 \%$ of hospitalizations include an ICU stay, and a small fraction of patients $(2-4 \%)$ require mechanical ventilation.

\section{What this paper contributes to our knowledge}

During an 8-year period from 2000 to 2008, the use of noninvasive ventilation increased by 5 -fold, whereas the use of invasive ventilation declined for treatment of AEs. This was associated with a trend toward improved outcome in patients requiring ventilator support.

sis, ${ }^{21}$ or COPD (ICD-9-CM codes 490-492 and 496) since mechanical ventilation in these patients may result from these secondary diagnoses rather than AE itself (Fig. 1). We included patients with ICD-9-CM codes indicating the presence of sleep apnea syndromes in our analysis because of the overlap between sleep-disordered breathing and asthma, especially difficult-to-control asthma. ${ }^{22}$ For our analysis of mechanical ventilation use and outcomes, we excluded admissions with missing data regarding mortality, age, and gender.

\section{Outcomes}

Our primary outcome of interest was use of any type of mechanical ventilation. We used ICD-9-CM codes to identify patients receiving NIV (code 93.90) or invasive mechanical ventilation (code 96.7X). NIS includes the hospital day mechanical ventilation is initiated; we were thus able to determine time-to-mechanical ventilation in days after admission. Because mechanical ventilation use for AEs is typically initiated around the time of admission, our primary analysis examined mechanical ventilation use initiated only on the first or second hospital day. We also examined use of invasive mechanical ventilation and NIV separately. For these analyses, we classified those who received both NIV and invasive mechanical ventilation during the first 2 hospital days with those receiving only invasive mechanical ventilation. To account for the increasing prevalence of sleep-disordered breathing and the utilization of NIV for these diagnoses, we also examined the use of NIV by excluding patients who had obstructive sleep apnea (OSA) coded as a secondary diagnosis.

We used the discharge destination variable to determine in-hospital mortality and whether surviving patients were 


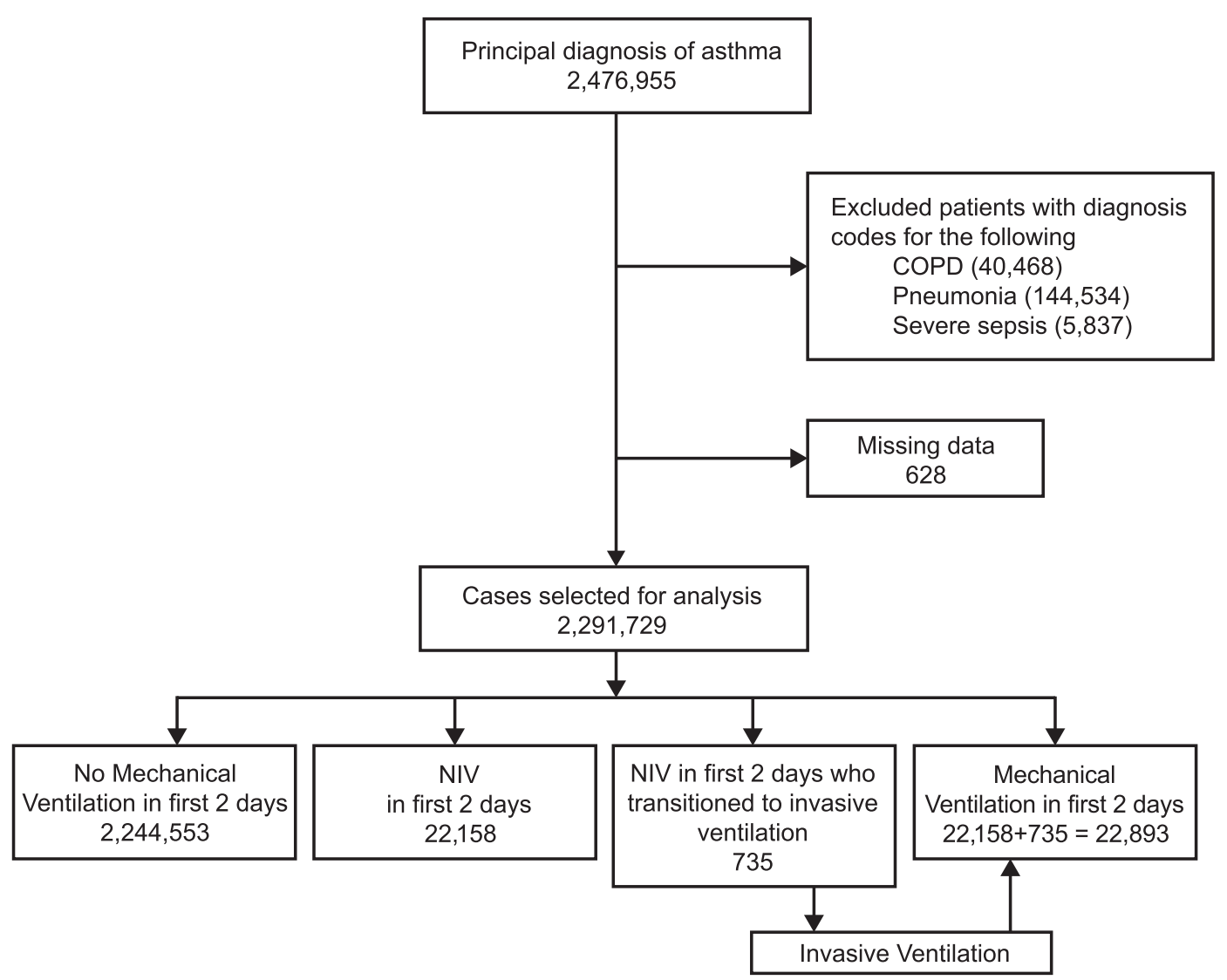

Fig. 1. Selection of asthma cases for this study. NIV = noninvasive ventilation.

discharged to a nursing home or home with home health care.

As secondary outcomes, we examined hospital stay, prolonged invasive mechanical ventilation (defined by invasive mechanical ventilation on 4 or more hospital days), and whether the patient developed a pneumothorax (ICD9-CM codes 512 and 998.2) and received a tracheostomy (ICD-9-CM codes 31.1 and 31.2).

\section{Definition of Variables}

We used NIS variables to identify patient age, gender, and race. Information of race was missing in $\sim 20 \%$ of records through the different years. We classified those with missing race information together in an "unknown" group. We used hospital teaching status, size, and ownership categories provided by NIS.

We used ICD-9-CM codes to identify comorbid conditions based on prior work or our clinical experience that would influence either the decision to use mechanical ventilation or the outcome of the AE. These included diabetes mellitus (code 250), congestive heart failure (code 428), cancer (codes 140-208), morbid obesity (codes 278.01 and V85.4), alcoholism (codes 291, 303.0, 303.9, and 305.0), and smoking (codes 305.1 and V15.82). We assessed the overall burden of comorbid conditions using Deyo's modification of the Charlson comorbidity index. ${ }^{23}$ The Charlson comorbidity index is the sum of weights assigned to each of 17 comorbid diseases, with higher scores corresponding to a greater comorbidity burden. In our population, the Charlson comorbidity index ranged from 1 to 16 .

\section{Statistical Analysis}

We performed all analysis using statistical software (Stata/IC 11.0, StataCorp, College Station, Texas). We first used Strata weights and survey estimation commands to generate national estimates of the number of hospitalizations for AEs in each study year and the proportion of those hospitalizations during which patients received mechanical ventilation.

To examine more closely changes in mechanical ventilation use over this period, we compared patients admitted with AEs in 2000 with those admitted in 2008 using the Pearson chi-square test for categorical variables; we used Student's $t$ test or the Wilcoxon rank-sum test to compare continuous variables as appropriate for their distribution. We created dummy variables for each age group and race 


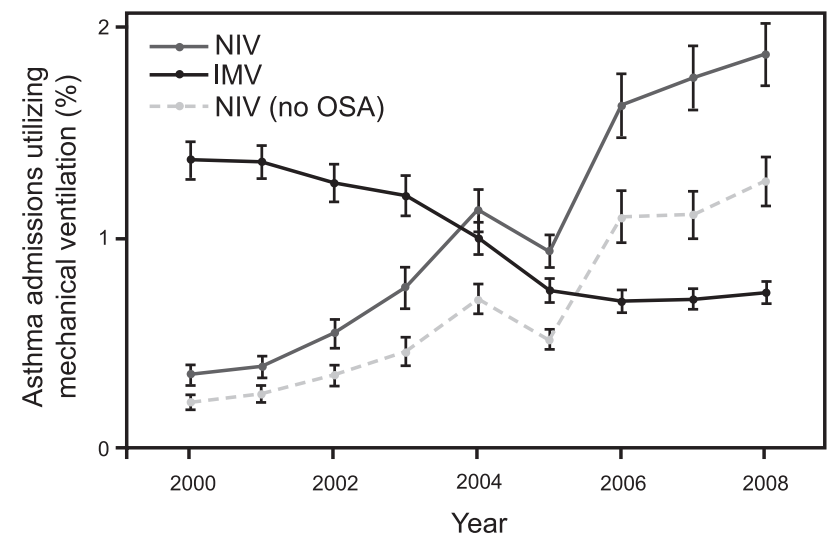

Fig. 2. Utilization of noninvasive and invasive mechanical ventilation in asthma. Bars represent standard error. NIV = noninvasive ventilation; IMV = invasive mechanical ventilation; OSA = obstructive sleep apnea.

and insurance categories to compare them individually. To describe changes in the characteristics of patients receiving each form of mechanical ventilation, we made similar bivariate comparisons between patients receiving invasive mechanical ventilation for AEs during the years 2000 and 2008 and also between those receiving NIV in the same years. We made these comparisons both overall and in the subgroups that received no mechanical ventilation, NIV only, or invasive mechanical ventilation.

We then used multivariate logistic regression to examine the relative odds of receiving either form of mechanical ventilation in 2008 versus 2000, adjusting for potential confounders. First, we tested the bivariate association of putative risk factors with receipt of mechanical ventilation and then included those found significant at $P<.10$ in our final multivariate model. We also included factors clinically known to influence receipt of either form of mechanical ventilation regardless of their significance. To account for interactions between variables, we examined all twoway interaction terms and retained those found significant in our model. For the variables we included in our final model, both the tolerance and the variance inflation factor were close to unity, indicating minimal collinearity. We then forced year into this final model to determine whether it added significantly to the model and to estimate the magnitude of any change from 2000 to 2008 . In sensitivity analyses, we examined all mechanical ventilation regardless of whether it was initiated during the first 2 hospital days, with results that were qualitatively similar, so we do not present these analyses. We then repeated this analysis using receipt of invasive mechanical ventilation as the outcome variable, excluding those patients who received NIV. Finally, we performed the analysis using receipt of NIV as the outcome variable, excluding those who received invasive mechanical ventilation.

We then constructed a multivariate model using techniques similar to those described above to determine whether in- hospital mortality changed from 2000 to 2008 . We also compared risk of mortality in our 3 a priori defined subgroups: (1) no mechanical ventilation, (2) invasive mechanical ventilation, and (3) NIV only. We repeated our mortality analysis considering only those deaths that occurred within 3 days of admission; the results were similar and are not presented. We used a similar approach to determine whether hospital stay had changed from 2000 to 2008 and whether this pattern differed among patients receiving invasive mechanical ventilation, NIV, or neither. In this analysis, we used log (hospital stay) as our outcome variable since hospital stay has a highly skewed distribution, and we used linear rather than logistic regression.

\section{Results}

We identified a total of 2,476,955 hospitalizations with the principal diagnosis of $\mathrm{AE}$ in adults over 18 years of age from 2000 to 2008 in the United States. After excluding those with COPD, pneumonia, and severe sepsis as secondary diagnoses, we were left with 2,291,729 discharges. The number of hospitalizations for AEs increased by $15.8 \%$ over the 9 -year study period (from 226,385 discharges in 2000 to 262,190 in 2008), as shown in Figure 2. The age of patients hospitalized with AEs increased from 2000 to 2008 (50.6 vs 55.2 years, $P<.001$ ); the proportion of hospitalizations involving patients 50 years old or older increased from $47.9 \%$ to $60.7 \%$ (Appendixes 1 and 2). (See the supplementary materials at http:// www.rcjournal.com.) The degree of comorbidity as measured by the Charlson comorbidity index also increased. For clarity, the demographic and clinical characteristics of patients hospitalized with AEs for the years 2000 and 2008 are presented in Tables 1 and 2. Appendixes 6-8 show the characteristics of patients in each individual year from 2000 to 2008 . 


\section{Utilization of Mechanical Ventilation for Asthma Exacerbations}

Table 1. Demographic and Clinical Characteristics of Patients Discharged With Asthma Exacerbations: Comparison of 2000 and 2008

\begin{tabular}{|c|c|c|c|}
\hline Patient Characteristics & 2000 & 2008 & $P$ \\
\hline Total & 226,385 & 262,190 & \\
\hline Mean age \pm SD y & $50.6 \pm 18.1$ & $55.2 \pm 17.8$ & $<.001$ \\
\hline \multicolumn{4}{|l|}{ Age category, $\%$} \\
\hline $18-34 y^{*}$ & 20.4 & 13.1 & $<.001$ \\
\hline $35-49 y^{*}$ & 31.7 & 26.2 & $<.001$ \\
\hline $50-64 y^{*}$ & 23.3 & 29.5 & $<.001$ \\
\hline $65-79 y^{*}$ & 17 & 20.2 & $<.001$ \\
\hline 80 y or older* & 7.6 & 11 & $<.001$ \\
\hline \multicolumn{4}{|l|}{ Gender, $\%$} \\
\hline Female* & 73.8 & 72.4 & 0.004 \\
\hline \multicolumn{4}{|l|}{ Race, $\%$} \\
\hline Caucasian & 43.8 & 46.9 & 0.20 \\
\hline African-American & 18.4 & 19.9 & 0.41 \\
\hline Hispanic & 9.5 & 10 & 0.75 \\
\hline Asian or Pacific Islander & 1.6 & 1.5 & 0.70 \\
\hline Other & 2.7 & 3.0 & 0.81 \\
\hline Unknown* & 23.9 & 18.6 & 0.04 \\
\hline \multicolumn{4}{|l|}{ Payer, $\%$} \\
\hline Medicare* & 30.5 & 40 & $<.001$ \\
\hline Medicaid & 20.2 & 19.2 & 0.51 \\
\hline Private* & 36.9 & 28.3 & $<.001$ \\
\hline Self & 8.3 & 8.4 & 0.89 \\
\hline Other & 4.2 & 4.2 & 0.9 \\
\hline \multicolumn{4}{|l|}{ Charlson/Deyo comorbidity index,* \% } \\
\hline $1-2 *$ & 94.9 & 86.2 & $<.001$ \\
\hline $3-4 *$ & 3.8 & 10.6 & $<.001$ \\
\hline $5-6^{*}$ & 0.1 & 1.7 & $<.001$ \\
\hline 7 or more & 1.2 & 1.5 & 0.07 \\
\hline \multicolumn{4}{|l|}{ Comorbidities, $\%$} \\
\hline Diabetes mellitus* & 16.5 & 26.7 & $<.001$ \\
\hline Congestive heart failure* & 6.7 & 11.9 & $<.001$ \\
\hline Morbid obesity* & 3.2 & 9.4 & $<.001$ \\
\hline Cancer* & 4.0 & 6.2 & $<.001$ \\
\hline Alcoholism* & 1.6 & 2.1 & $<.001$ \\
\hline Smoking* & 15 & 33.2 & $<.001$ \\
\hline $\mathrm{OSA}^{*}$ & 2.7 & 10.3 & $<.001$ \\
\hline \multicolumn{4}{|l|}{ Hospital characteristics, $\%$} \\
\hline Teaching & 41.6 & 42.2 & 0.88 \\
\hline \multicolumn{4}{|l|}{ Hospital size } \\
\hline Small & 12.5 & 14.2 & $<.001$ \\
\hline Medium & 31.9 & 26.1 & $<.001$ \\
\hline Large & 55.6 & 59.7 & $<.001$ \\
\hline \multicolumn{4}{|l|}{ Hospital ownership } \\
\hline Government, nonfederal & 14.7 & 13.5 & $<.001$ \\
\hline Private, nonprofit & 73.3 & 72.3 & 0.74 \\
\hline Private, investor-owned & 12.0 & 14.2 & $<.001$ \\
\hline \multicolumn{4}{|l|}{ Mechanical ventilation, $n(\%)$} \\
\hline Total NIV* & $796(0.35)$ & $4908(1.9)$ & $<.001$ \\
\hline NIV in patients without OSA* & $486(0.21)$ & $2987(1.1)$ & $<.001$ \\
\hline Total invasive mechanical ventilation* & $3095(1.4)$ & $1931(0.73)$ & $<.001$ \\
\hline Any mechanical ventilation (invasive mechanical ventilation + NIV) & $3891(1.8)$ & $6839(2.6)$ & $<.001$ \\
\hline $\begin{array}{l}\text { * Significant difference between } 2000 \text { and } 2008 \text { at } P<.05 \\
\text { OSA }=\text { obstructive sleep apnea } \\
\text { NIV = noninvasive ventilation }\end{array}$ & & & \\
\hline
\end{tabular}




\section{Utilization of Mechanical Ventilation for Asthma Exacerbations}

Table 2. Patient Characteristics With Noninvasive and Invasive Mechanical Ventilation Use Among Adults Admitted With Asthma Exacerbations During 2000 and 2008

\begin{tabular}{|c|c|c|c|c|}
\hline \multirow{2}{*}{ Patient Characteristics } & \multicolumn{2}{|c|}{ NIV in First 2 Days } & \multicolumn{2}{|c|}{$\begin{array}{c}\text { Invasive Mechanical Ventilation in } \\
\text { First } 2 \text { Days }\end{array}$} \\
\hline & 2000 & 2008 & 2000 & 2008 \\
\hline Total & 796 & 4908 & 3095 & 1931 \\
\hline Mean age \pm SD y & $50.2 \pm 14.7$ & $54.6 \pm 15.8^{*}$ & $47.5 \pm 17.3$ & $48.1 \pm 17.2$ \\
\hline \multicolumn{5}{|l|}{ Age category, $\%$} \\
\hline $18-34$ y & 14.5 & 10.5 & 26.5 & 24.9 \\
\hline $35-49 y$ & 37.1 & 29.6 & 31.9 & 30.1 \\
\hline $50-64$ y & 30.2 & 32.9 & 22.9 & 26.2 \\
\hline $65-79 y$ & 15.1 & 19.7 & 13.7 & 13.3 \\
\hline 80 y or older & 3.1 & 7.3 & 5.1 & 5.5 \\
\hline \multicolumn{5}{|l|}{ Sex, $\%$} \\
\hline Male & 27.0 & 34.1 & 35.6 & 32.5 \\
\hline \multicolumn{5}{|l|}{ Race, $\%$} \\
\hline Caucasian & 42.3 & 45.7 & 38.5 & 44.9 \\
\hline African-American & 36.7 & 30.3 & 26.6 & 29.3 \\
\hline Hispanic & 8.0 & 11.1 & 14.5 & 9.0 \\
\hline Asian & - & 1.6 & 5.7 & $2.5^{*}$ \\
\hline Other & 7.9 & 2.9 & 4.4 & 5.9 \\
\hline Unknown & 5.0 & 8.5 & 10.3 & 8.4 \\
\hline \multicolumn{5}{|l|}{ Payer, $\%$} \\
\hline Medicare & 33.3 & $43.8^{*}$ & 21.7 & 27.3 \\
\hline Medicaid & 28.8 & 21.6 & 26.6 & 23 \\
\hline Private & 30.4 & 24.2 & 36.3 & $28.3^{*}$ \\
\hline Self & 6.4 & 6.3 & 10.8 & 14.2 \\
\hline Other & 1.2 & 4.2 & 4.6 & 7.2 \\
\hline \multicolumn{5}{|c|}{ Charlson/Deyo comorbidity index, $\%$} \\
\hline $1-2$ & 94.9 & $82.5^{*}$ & 95.4 & $85.9^{*}$ \\
\hline $3-4$ & 3.2 & $14.5^{*}$ & 3.8 & $10.7^{*}$ \\
\hline $5-6$ & & 2.3 & 0.1 & $2.5^{*}$ \\
\hline 7 or more & 1.8 & 0.8 & 0.7 & 0.8 \\
\hline \multicolumn{5}{|l|}{ Co-morbidities, \% } \\
\hline Diabetes mellitus & 27.4 & 34.9 & 12.3 & $23.8^{*}$ \\
\hline Congestive heart failure & 19.7 & 22.4 & 7.9 & $13.5^{*}$ \\
\hline Morbid obesity & 17.5 & 24.9 & 2.5 & $8.9^{*}$ \\
\hline Cancer & 2.5 & 5.2 & 2.3 & 4.1 \\
\hline Alcoholism & & 2.5 & 2.5 & $5.7^{*}$ \\
\hline Smoking & 20.4 & $36.8^{*}$ & 12.4 & $34.7^{*}$ \\
\hline \multicolumn{5}{|l|}{ Hospital Characteristics, $\%$} \\
\hline Teaching & 56.8 & 56.6 & 56.7 & 55.3 \\
\hline \multicolumn{5}{|l|}{ Hospital size } \\
\hline Small & 10.1 & 14.3 & 12.9 & $7.6^{*}$ \\
\hline Medium & 26.0 & 23.0 & 34.5 & 30.5 \\
\hline Large & 63.9 & 62.7 & 52.5 & $61.9^{*}$ \\
\hline \multicolumn{5}{|l|}{ Hospital ownership } \\
\hline Government, nonfederal & 12.6 & 14.6 & 19.1 & 18.1 \\
\hline Private, nonprofit & 78.9 & 75.5 & 69.8 & 69.3 \\
\hline Private, investor-owned & 8.4 & 9.8 & 11.1 & 12.6 \\
\hline
\end{tabular}


Table 3. Risk of Death in Patients Admitted With Asthma Exacerbations: 2000 versus 2008

\begin{tabular}{|c|c|}
\hline Models & $\begin{array}{l}\text { Risk of Death in } \\
2000 \text { vs 2008, } \\
\text { Odds Ratio } \\
(95 \% \text { CI })\end{array}$ \\
\hline Unadjusted & $0.83(0.66-1.04)$ \\
\hline $\begin{array}{l}\text { Adjusted for demographics } \\
\text { (age, gender, race })^{*}\end{array}$ & $0.67(0.53-0.84)$ \\
\hline $\begin{array}{l}\text { Adjusted for demographics and } \\
\text { comorbidity index* }\end{array}$ & $0.58(0.45-0.73)$ \\
\hline $\begin{array}{l}\text { Adjusted for above and mechanical } \\
\text { ventilation* }\end{array}$ & $0.64(0.51-0.81)$ \\
\hline \multicolumn{2}{|l|}{$\begin{array}{l}\text { Subgroup analysis adjusting for } \\
\text { demographics and comorbidity index }\end{array}$} \\
\hline $\begin{array}{l}\text { Among those not receiving mechanical } \\
\text { ventilation* }\end{array}$ & $0.57(0.45-0.73)$ \\
\hline Among those receiving early NIV & $0.41(0.07-2.14)$ \\
\hline $\begin{array}{l}\text { Among those receiving early invasive mechanical } \\
\text { ventilation }\end{array}$ & $1.08(0.63-1.84)$ \\
\hline $\begin{array}{l}* \text { Significant difference between } 2000 \text { and } 2008 \text { at } P<.05 \\
\text { NIV = noninvasive ventilation }\end{array}$ & \\
\hline
\end{tabular}

\section{Use of Mechanical Ventilation}

In unadjusted analyses, the proportion of patients hospitalized for AEs receiving mechanical ventilation (invasive mechanical ventilation or NIV) increased by $45 \%$ from 2000 to 2008. This was due primarily to an increase in the proportion of hospitalizations involving NIV by $>400 \%$, from $0.35 \%$ of all AEs in 2000 to $1.9 \%$ in 2008 , an annualized increase of $49 \%$. Conversely, the proportion of $\mathrm{AE}$ hospitalizations involving invasive mechanical ventilation fell by $50 \%$, from $1.4 \%$ to $0.73 \%$ (see Table 1 and Fig. 2), an annualized decrease of 5.3\%. After adjustment for potential confounding factors, the odds of patients hospitalized with AEs in 2008 receiving any form of mechanical ventilation were over twice that in 2000 (odds ratio [OR] 2.43, 95\% CI 1.19-4.94) (Appendix 3). This was accompanied by a decrease in the odds of receiving invasive mechanical ventilation by $50 \%$ (OR $0.52,95 \%$ CI $0.46-0.59)$ and a tripling of the odds of receiving NIV (OR 3.47, 95\% CI 2.94-4.10) (Appendixes 4 and 5). Even after exclusion of patients with OSA, the proportion receiving NIV rose by $>500 \%(0.21 \%$ in 2000 to $1.1 \%$ in 2008) (see Table 1).

\section{Outcomes}

Between 2000 and 2008, the case fatality rate among patients hospitalized with AEs decreased ( $0.33 \%$ vs $0.28 \%)$. The case fatality rates among patients receiving no mechanical ventilation, NIV, and invasive mechanical ventilation were unchanged between 2000 and 2008, although the 3-day mortality for patients who did not require mechanical ventilation was lower in 2008 compared with 2000. However, after adjusting for demographic, clinical, and hospital characteristics, the odds of in-patient mortality were significantly lower in 2008 than in 2000 (OR 0.64, 95\% CI 0.51-0.81) (Table 3).

When we examined subgroups defined by mechanical ventilation use, we found that the odds of in-hospital death

Table 4. Outcomes of Patients With Asthma Exacerbations: Comparison Between 2000 and 2008

\begin{tabular}{|c|c|c|c|c|c|c|}
\hline & \multicolumn{3}{|c|}{2000} & \multicolumn{3}{|c|}{2008} \\
\hline & $\begin{array}{l}\text { No Mechanical } \\
\text { Ventilation }\end{array}$ & NIV & $\begin{array}{c}\text { Invasive Mechanical } \\
\text { Ventilation }\end{array}$ & $\begin{array}{l}\text { No Mechanical } \\
\text { Ventilation }\end{array}$ & NIV & $\begin{array}{c}\text { Invasive Mechanical } \\
\text { Ventilation }\end{array}$ \\
\hline All cause in-hospital mortality, $\%$ & 0.24 & 1.22 & 6.37 & 0.21 & 0.84 & 6.92 \\
\hline 3-d mortality, \% & 0.08 & & 2.3 & $0.05^{*}$ & 0.6 & 4.5 \\
\hline Prolonged mechanical ventilation ( $>96 \mathrm{~h}$ ) & & & 23.1 & & & 18.2 \\
\hline Tracheostomy, \% & & & 0.8 & & & 1.5 \\
\hline Pneumothorax, \% & & & 0.9 & & & 1.2 \\
\hline \multicolumn{7}{|l|}{ Disposition in survivors, $\%$} \\
\hline Home & 89.3 & 76.9 & 75.6 & $84.5^{*}$ & 76.2 & 70.9 \\
\hline Home with home care & 4.3 & 15.5 & 7.0 & $7.7^{*}$ & 13.2 & $11.8 *$ \\
\hline Inter-hospital transfer & 0.7 & 0.6 & 5.6 & 0.7 & 1.0 & 4.6 \\
\hline Skilled nursing facility $\dagger$ & 3.5 & 5.1 & 7.0 & $4.7 *$ & 6.3 & 9.0 \\
\hline AMA/unknown & 2.3 & 1.9 & 5.1 & 2.4 & 3.4 & 3.6 \\
\hline Median hospital stay, d (interquartile range) & $3(2-5)$ & $4(2-7)$ & $5(3-8)$ & $3(2-5)$ & $4(2-6)$ & $5(3-8)$ \\
\hline $\begin{array}{l}\text { * Significant difference between } 2000 \text { and } 2008 \text { at } P<.05 \\
\dagger \text { Also includes intermediate care } \\
\text { NIV = noninvasive ventilation } \\
\text { AMA = against medical advice }\end{array}$ & & & & & & \\
\hline
\end{tabular}


Table 5. Predictors of Mortality in Asthma Exacerbation

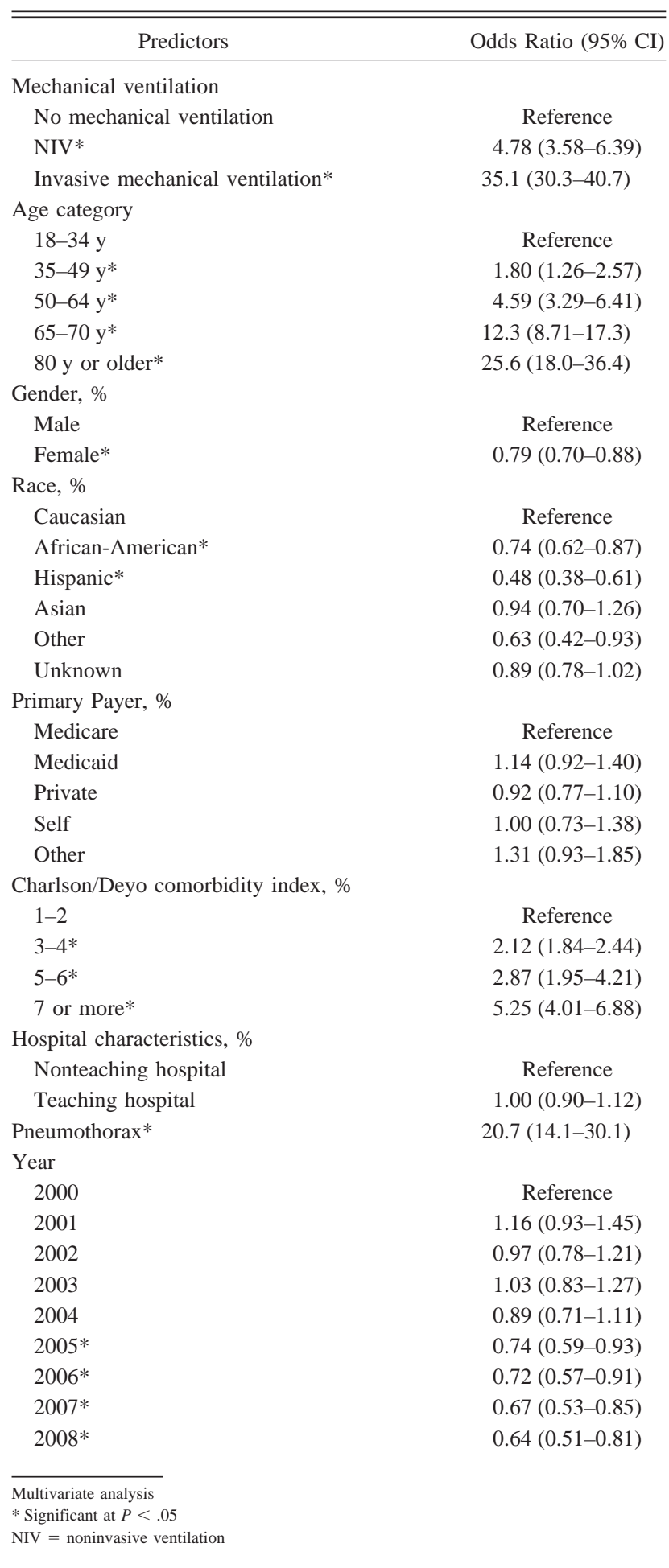

decreased among patients not receiving mechanical ventilation (OR 0.57, 95\% CI 0.45-0.73) and those receiving NIV (OR 0.41, 95\% CI 0.07-2.14), although the decrease in the latter was not significant. In addition, the decrease in the number of patients receiving invasive mechanical ventilation, who have the greatest risk, also contributed to the overall improved mortality. Among patients receiving any form of mechanical ventilation, both the unadjusted and adjusted mortalities were not different between 2000 and 2008 (Tables 3 and 4). Age and receipt of mechanical ventilation were the most influential predictors of mortality in patients with asthma. The OR for mortality compared with patients who did not receive mechanical ventilation increased from 4.78 among those who received NIV only (95\% CI 3.58-6.39) to 35.1 among those who received invasive mechanical ventilation as their initial form of mechanical ventilation (95\% CI 30.3-40.7) (Table 5).

The median stay of patients requiring invasive mechanical ventilation or NIV was similar in 2000 and 2008 (see Table 4). Patients who initially required NIV and later required invasive mechanical ventilation had a similar hospital stay in 2000 (4.5 d, interquartile range 2.5-11) and 2008 (6.5 d, interquartile range 4-10); their hospital stay was not significantly different from that of patients who required invasive mechanical ventilation from the outset.

The proportion of patients who received prolonged invasive mechanical ventilation ( $\geq 96 \mathrm{~h}$ ) was similar in 2000 and 2008 (23.1\% vs $18.2 \%)$. The rates of pneumothoraces and tracheostomies were not significantly different between 2000 and 2008 (see Table 4). In unadjusted analyses, survivors were more likely to be discharged to a health care facility (generally, a skilled nursing facility) or home with home health care in 2008. Detailed outcomes of patients for each individual year classified by utilization of mechanical ventilation are shown in Appendix 9.

\section{Discussion}

We report that, from 2000 to 2008, a 5-fold increase in the use of NIV led to a significant increase in the overall use of mechanical ventilation among adults hospitalized with AEs, despite a significant decline in invasive mechanical ventilation. The increment in utilization of NIV was the same even after excluding patients with OSA. This increase also persisted after adjusting for the fact that adults hospitalized for AEs in 2008 were older and had more comorbidities. The adjusted odds of receiving mechanical ventilation more than doubled, and NIV use was more than 3 times higher in 2008, whereas invasive mechanical ventilation use declined by nearly 2 -fold. During this same period, the odds of mortality, adjusted for differences in patient characteristics, decreased by one third.

Our finding of a remarkable increase in use of NIV is consistent with several single-center reports of increased use of NIV for asthma. ${ }^{6-19,24}$ Like us, the authors noted that more NIV use was associated with less invasive mechanical ventilation use and shorter hospital stay. Although 
our administrative data do not allow us to confirm the improvement in physiological parameters (eg, $\mathrm{FEV}_{1}$ and arterial $\mathrm{pH}$ ) that has been reported, ${ }^{15}$ it is possible that such changes contributed to our observed decrease in riskadjusted mortality.

We observed that the overall case fatality rate of AEs remained unchanged from 2000 to 2008. This is consistent with other reports on asthma trends. ${ }^{25,26}$ However, after adjusting for changes in demographical and clinical characteristics, we found that the risk of mortality associated with hospitalization for acute asthma in 2008 was just 0.64 times that in 2000. To our knowledge, our study is the first to describe this remarkable decline. Although we cannot ascertain the reasons for this improvement from our administrative data sources, the national representation of our results makes them even more noteworthy.

It is unclear whether this declining mortality is related to changes in the patterns of mechanical ventilation since there have been substantial improvements in the management of both $\mathrm{AEs}^{27}$ and respiratory failure more generally, ${ }^{28}$ including increased use of protocols ${ }^{29,30}$ and quality improvement projects ${ }^{31,32}$ centered on the care of patients admitted with AEs. Certainly, our findings of exponential increases in the adjusted risk of mortality as patients move from requiring NIV (OR 4.78) to invasive mechanical ventilation (OR 35.1) likely reflect increasing severity of illness leading to increasing mortality. However, the phenomenon of a shift to the use of predominantly NIV and stable case fatality rates as well as hospital stay in both the invasive mechanical ventilation and NIV cohorts suggests that initial NIV use may spare some patients the risks associated with invasive mechanical ventilation. This raises the possibility that the use of NIV in place of invasive mechanical ventilation in appropriate patients may lower the risk of mortality associated with AE hospitalizations.

We must acknowledge several important limitations of our study. First, although ICD-9-CM codes for AEs have been previously validated and used, we cannot exclude the possibility of variations in accuracy of coding between hospitals. ${ }^{33}$ Second, important clinical detail such as the severity of asthma exacerbation, appropriate use of therapies (eg, steroids and bronchodilators), environment of provision of NIV (ICU vs non-ICU), and baseline pulmonary function cannot be ascertained in NIS. Particularly, provision of NIV may frequently occur outside of the ICU setting and would obscure important severity aspects in analysis of administrative data. Such detail, if available, would allow for more robust analysis of the predictors of mortality and need for mechanical ventilation. Similarly, although we adjusted our analysis for comorbid conditions, ICD-9-CM codes do not allow the detection of important clinical severity differences within each comorbid condition. Such differences may be significant confounders, for example, the association of obesity and asthma. ${ }^{34}$
Third, although procedure codes for invasive mechanical ventilation are reliable, ${ }^{35}$ the provision of such procedures may be unrelated to the asthma exacerbation itself. We tried to circumvent this problem by examining only mechanical ventilation administered during the first 2 days of AE hospitalization and by excluding patients with secondary diagnoses of COPD, pneumonia, and severe sepsis, common reasons for initiation of respiratory support. Nevertheless, other diagnoses such as OSA may be the reason for the presence of these codes. If patients with underlying sleep apnea syndromes hospitalized with asthma exacerbations continued their prescribed home NIV in the hospital, it is likely that our results would be confounded by the inclusion of patients with a lesser severity of illness in the NIV cohort, and our results would be biased toward lower risk-adjusted mortality in patients receiving NIV. However, exclusion of such patients did not change the proportional increase in the utilization of NIV. Finally, since NIS does not contain patient identifiers, we could not identify readmissions of the same patient. This meant we could not examine readmissions, an important outcome. It also means that we slightly underestimated the precision of our estimates since our statistical methods assume independent observations.

Despite its limitations, we believe that our study provides important information about trends in mechanical ventilation use for AEs and associated outcomes. The rapid increase in the proportion of patients receiving NIV has been associated with a significant decrease in adjusted mortality. Whereas this does not suggest a causal relationship, NIV use may be associated with improved mortality either by avoiding the risks of invasive mechanical ventilation or by allowing use of mechanical ventilation in a broader spectrum of patients with AEs. Because observational studies of new technologies are subject to a number of biases, we believe that more rigorous studies, such as randomized trials, should be a high priority. This need is supported by the risk of complications of NIV, which may be increased as it is used in less intensively monitored settings, and by the concern that NIV use may delay the use of needed invasive mechanical ventilation. ${ }^{36}$

\section{REFERENCES}

1. Akinbami LJ, Bailey C, Zahran HS, King M, Johnson CA, Liu, X. Trends in asthma prevalence, health care use, and mortality in the United States, 2001-2010. NCHS Data Brief 2012;(94):1-8

2. Gupta D, Keogh B, Chung KF, Ayres JG, Harrison DA, Goldfrad C, et al. Characteristics and outcome for admissions to adult, general critical care units with acute severe asthma: a secondary analysis of the ICNARC Case Mix Programme Database. Crit Care 2004;8(2): R112-R121.

3. Pendergraft TB, Stanford RH, Beasley R, Stempel DA, Roberts C, McLaughlin T. Rates and characteristics of intensive care unit admissions and intubations among asthma-related hospitalizations. Ann Allergy Asthma Immunol 2004;93(1):29-35. 


\section{Utilization of Mechanical Ventilation for Asthma Exacerbations}

4. Eisner MD, Boland M, Tolstykh I, Mendoza G, Iribarren C. Intensive care unit admission for asthma: a marker for severe disease. J Asthma 2005;42(5):315-323.

5. Afessa B, Morales I, Cury JD. Clinical course and outcome of patients admitted to an ICU for status asthmaticus. Chest 2001;120(5): 1616-1621.

6. Krishnan V, Diette GB, Rand CS, Bilderback AL, Merriman B, Hansel NN, Krishnan JA. Mortality in patients hospitalized for asthma exacerbations in the United States. Am J Respir Crit Care Med 2006;174(6):633-638.

7. Braman SS, Kaemmerlen JT. Intensive care of status asthmaticus. A 10-year experience. JAMA 1990;264(3):366-368.

8. Shapiro JM. Intensive care management of status asthmaticus. Chest 2001;120(5):1439-1441.

9. Burns KE, Adhikari NK, Keenan SP, Meade MO. Noninvasive positive pressure ventilation as a weaning strategy for intubated adults with respiratory failure. Cochrane Database Syst Rev 2010(8): CD004127.

10. Garpestad E, Brennan J, Hill NS. Noninvasive ventilation for critical care. Chest 2007;132(2):711-720.

11. Ram FS, Picot J, Lightowler J, Wedzicha JA. Non-invasive positive pressure ventilation for treatment of respiratory failure due to exacerbations of chronic obstructive pulmonary disease. Cochrane Database Syst Rev 2004(3):CD004104.

12. Brochard L, Mancebo J, Wysocki M, Lofaso F, Conti G, Rauss A et al. Noninvasive ventilation for acute exacerbations of chronic obstructive pulmonary disease. N Engl J Med 1995;333(13):817-822.

13. Gray A, Goodacre S, Newby DE, Masson M, Sampson F, Nicholl J. Noninvasive ventilation in acute cardiogenic pulmonary edema. N Engl J Med 2008;359(2):142-151.

14. Rocco M, Dell'Utri D, Morelli A, Spadetta G, Conti G, Antonelli M, Pietropaoli P. Noninvasive ventilation by helmet or face mask in immunocompromised patients: a case-control study. Chest 2004; 126(5):1508-1515.

15. Ram FS, Wellington S, Rowe BH, Wedzicha JA. Non-invasive positive pressure ventilation for treatment of respiratory failure due to severe acute exacerbations of asthma. Cochrane Database Syst Rev 2005(1):CD004360.

16. Meduri GU, Cook TR, Turner RE, Cohen M, Leeper KV. Noninvasive positive pressure ventilation in status asthmaticus. Chest 1996; 110(3):767-774

17. Soroksky A, Stav D, Shpirer I. A pilot prospective, randomized, placebo-controlled trial of bilevel positive airway pressure in acute asthmatic attack. Chest 2003;123(4):1018-1025.

18. Fernández MM, Villagrá A, Blanch L, Fernández R. Non-invasive mechanical ventilation in status asthmaticus. Intensive Care Med 2001;27(3):486-492.

19. Soma T, Hino M, Kida K, Kudoh S. A prospective and randomized study for improvement of acute asthma by non-invasive positive pressure ventilation (NPPV). Intern Med 2008;47(6):493-501.

20. Healthcare Cost and Utilization Project-HCUP. Introduction to the HCUP Nationwide Inpatient Sample (NIS). http://www.hcup-us.
ahrq.gov/db/nation/nis/NIS_2007_INTRODUCTION.pdf. Accessed Nov 2, 2011

21. Martin GS, Mannino DM, Eaton S, Moss M. The epidemiology of sepsis in the United States from 1979 through 2000. N Engl J Med 2003;348(16):1546-1554

22. Camargo CA Jr, Weiss ST, Zhang S, Willett WC, Speizer FE. Prospective study of body mass index, weight change, and risk of adult-onset asthma in women. Arch Intern Med 1999;159(21):25822588.

23. Deyo RA, Cherkin DC, Ciol MA. Adapting a clinical comorbidity index for use with ICD-9-CM administrative databases. J Clin Epidemiol 1992;45(6):613-619.

24. Gupta D, Nath A, Agarwal R, Behera D. A prospective randomized controlled trial on the efficacy of noninvasive ventilation in severe acute asthma. Respir Care 2010;55(5):536-543.

25. McFadden ER Jr, Warren EL. Observations on asthma mortality. Ann Intern Med 1997;127(2):142-147.

26. Getahun D, Demissie K, Rhoads GG. Recent trends in asthma hospitalization and mortality in the United States. J Asthma 2005;42(5): 373-378.

27. Barnes PJ. Severe asthma: advances in current management and future therapy. J Allergy Clin Immunol 2012;129(1):48-59.

28. Boldrini R, Fasano L, Nava S. Noninvasive mechanical ventilation. Curr Opin Crit Care 2012;18(1):48-53.

29. Hartert TV, Togias A, Mellen BG, Mitchel EF, Snowden MS, Griffin MR. Underutilization of controller and rescue medications among older adults with asthma requiring hospital care. J Am Geriatr Soc 2000;48(6):651-657.

30. Johnson KB, Blaisdell CJ, Walker A, Eggleston P. Effectiveness of a clinical pathway for inpatient asthma management. Pediatrics 2000; 106(5):1006-1012.

31. Mayo PH, Weinberg BJ, Kramer B, Richman J, Seibert-Choi OS, Rosen MJ. Results of a program to improve the process of inpatient care of adult asthmatics. Chest 1996;110(1):48-52.

32. Evans R 3rd, LeBailly S, Gordon KK, Sawyer A, Christoffel KK, Pearce B. Restructuring asthma care in a hospital setting to improve outcomes. Chest 1999;116(4 Suppl 1):210S-216S.

33. Sawicki GS, Vilk Y, Schatz M, Kleinman K, Abrams A, Madden J. Uncontrolled asthma in a commercially insured population from 2002 to 2007: trends, predictors, and costs. J Asthma 2010;47(5): 574-580.

34. Farah CS, Kermode JA, Downie SR, Brown NJ, Hardaker KM, Berend $\mathrm{N}$, et al. Obesity is a determinant of asthma control independent of inflammation and lung mechanics. Chest 2011;140(3):659666

35. Quan H, Parsons GA, Ghali WA. Validity of procedure codes in International Classification of Diseases, 9th revision, clinical modification administrative data. Med Care 2004;42(8):801-809.

36. Esteban A, Frutos-Vivar F, Ferguson ND, Arabi Y, Apezteguía C, González M, et al. Noninvasive positive-pressure ventilation for respiratory failure after extubation. N Engl J Med 2004;350(24):24522460

This article is approved for Continuing Respiratory Care Education credit. For information and to obtain your CRCE

(free to AARC members) visit www.rcjournal.com

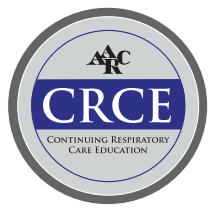

